\title{
Do que Se PODE LeR eM Clarice Lispector: SUBLIMAÇÃO E FEMININO *
}

\author{
Cristina Marcos ${ }^{\star \star}$
}

\begin{abstract}
RESUMO
Neste artigo, busca-se ler em Clarice Lispector não uma significação feminina da obra, mas de que modo sua escrita nos permite pensar certos modos de subjetivação do feminino. A leitura assim orientada levou-me a rever o conceito de sublimação e a pensar a obra como lugar privilegiado de inscrição de um gozo que se inscreve no texto pela voz. Trata-se não da apropriação do eu, mas da exibição da falta a ser do sujeito. A função primeira da escrita é menos a constituição do eu do escritor do que sua perda no texto e a inscrição de um gozo.
\end{abstract}

Palavras-chave: Feminino. Gozo. Sublimação. Psicanálise.

\section{What can we Read in Clarice Lispector? SublimATION AND THE FEMININE}

\begin{abstract}
In this paper, I try to read in Clarice Lispector's writing certain ways of subjectivation of the feminine (and not a feminine signification of her work). This approach has led me to a revision of the concept of sublimation and to see the text a locus in which the jouissance inscribes itself by the voice. What is at stake in her texts is the display of the manque à être of the subject, and not the appropriation of the ego. The primary function of writing is the inscription of the jouissance in the text.
\end{abstract}

Keywords: Feminine. Jouissance. Sublimation. Psychoanalysis.

* Este artigo é parte da minha tese de doutorado intitulada L'esthétique du souffle chez Clarice Lispector: Un certain destin du féminin, defendida na Universidade de Paris VII, sob a orientação do Prof. Patrick Guyomard.

$\star \star$ Psicanalista, Mestre em Literatura Brasileira pela UFMG. Doutora em Psicopatologia Fundamental e Psicanálise pela Universidade de Paris VII. Docente da PUC-Minas.

Rua Paschoal Carlos Magno, 68. Ouro Preto. 31310.510. Belo Horizonte. Minas Gerais.

E-mail: cristinamarcos@terra.com.br 


\section{CONSIDERAÇõES SOBRE A SUBLIMAÇão, A ARTE, O OBJETO E A PSICANÁLISE}

Se a obra coloca questões, como quer Gérard Wajcman (1998), ela também nos fornece respostas. A qual questão ela fornece uma resposta? - é justamente o enigma que me desafia. Na obra de Clarice Lispector, a resposta que ela é constitui-se para mim em uma questão. Proponho tomar a obra de Clarice como uma resposta, como um pensamento, mas acerca do quê? Acerca de um excesso do real e da insuficiência do simbólico para dar conta disto. Sabemos que certas manifestações da clínica do feminino, como um certo sentimento de depreciação tão frequente nas mulheres, a inibição que ganha um caráter particular, a falta de identidade cuja intensidade chama a atenção, os fenômenos corporais que escapam ao contrôle, os testemunhos de uma dor psíquica que parece ligada a uma ausência de si, entre outros, são tomadas como uma impossível reconciliação do simbólico com o real. Permanece a questão de se saber se a resposta de Clarice, sua obra, não seria uma barreira contra essas manifestações, uma outra via para o que se apresenta, a algumas mulheres, como sem saída.

Meu propósito é interrogar o feminino a partir da escrita de uma mulher. A questão se coloca do seguinte modo: o que a escrita dessa mulher pode nos ensinar sobre o feminino? É a partir do que eu chamei de uma estética do sopro, ${ }^{1}$ do que aparece no texto como murmúrio, intervalo, silêncio, que um saber sobre o feminino se inscreve.

A leitura da obra a partir dessa questão conduziu-me a rever o conceito de sublimação e a pensar a obra como lugar privilegiado de inscrição de um gozo, gozo que se inscreve no texto pela voz. A obra conduziu-me assim a falar de objeto, pois em Clarice Lispector trata-se de uma escrita na qual o que está em jogo é mais uma sonoridade que aponta para o objeto - a voz e sua pulsação - do que uma narrativa presa às categorias literárias tradicionais - autor, personagem, fatos. Claro, a letra é o suporte dessa escrita, mas me parece que o que há de singular nessa escrita, o que se repete, é menos uma depuração da letra até a sua materialidade do que uma pulsação, uma respiração do texto. Oriento-me por uma indicação da própria Clarice - a de que o sentido não vem pelas palavras, mas pela respiração.

Porque o recurso à literatura para falar do feminino ou porque a obra de Clarice Lispector interessaria à psicanálise? Muitas são as respostas. Sigo aqui uma orientação de Lacan que encontramos em um texto em homenagem à MerleauPonty (LACAN, 1961). A arte, segundo Lacan, nos dá a ver o que de outro modo não se veria, mantendo o que há de inapreensível no objeto. Saímos assim da metáfora do psicanalista como decifrador da arte para pensar a arte como aquilo que coloca questões ao psicanalista, decifradora ou causadora do analista/sujeito. A arte nos ensina modos de subjetivação que estão em jogo na clínica. Sendo assim interessa-me menos a caracterização de uma escrita como feminina do que o modo como a escrita de Clarice Lispector nos permite pensar certos modos de subjetivação femininos.

A escrita de Clarice assinalando um além da palavra, um impossível a dizer, é passível de nos ensinar sobre o feminino e sua relação com o real e com o gozo, 
com a parte da mulher que não se recobre pelo falo. Quais seriam as manifestações dessa parte da mulher? Graças a uma dicção particular, a estética do sopro, através da qual Clarice busca falar de um impossível além da linguagem, sua escrita pode nos fornecer elementos para pensar o feminino em sua relação com a criação, com o real e com o gozo.

Impõe-se a questão da relação de Clarice Lispector com sua vocação de mulher de letras. Qual é a função dessa escrita que quer se passar das palavras, que quer a sonoridade das palavras e seu silêncio, na qual o mais essencial não é a narrativa mas sua dissolução na matéria da linguagem? Dito de outro modo, a que vem esta escrita na qual a sonoridade das palavras é muito mais buscada do que o sentido e a narrativa, uma escrita que nos pede uma escuta que se deixe conduzir pela música das sílabas desconectadas do sentido.

Sua escrita parece ser menos uma escolha, do que a submissão a um processo, a resposta a um chamado imperativo e menos uma confissão pessoal, do que um percurso em direção ao impessoal. Menos que uma escrita do sujeito, trata-se de uma escrita do objeto.

O que não significa que os traços subjetivos não estão impressos no texto. A obra de Clarice Lispector constitui-se como uma teia na qual ela mesma, seu ego, é tecido. A dificuldade que temos em falar de autobiografia, mesmo se temos uma confusão entre autor e narrador, vem de uma deflação do imaginário que diz respeito ao ego e ao corpo, assim como ao texto ele mesmo que se despoja do sentido e da forma.

O conceito de sublimação é a tentativa mais avançada de Freud (1968) para dar conta da relação do artista com a criação em termos de destino da pulsão. Exaltado por uns e criticado por outros, este conceito sempre foi objeto de polêmicas. Mesmo em Freud não se tem um grande desenvolvimento teórico a respeito e as contradições e problemas encontrados permanecem. Entretanto Freud mantém uma coerência em relação à sublimação - ela é um modo de satisfação da pulsão que não passa pelo recalcamento e um dos destinos mais felizes da pulsão. A sublimação é a derivação da pulsão sexual em direção a um objeto não sexual socialmente reconhecido. $\mathrm{O}$ conceito é freqüentemente reduzido a uma vitória do intelecto sobre a sensação e levou a pensar em uma espécie de conciliação entre a pulsão e as exigências da cultura (Cf. FREUD, 1999). Entretanto encontramos, no próprio Freud, um limite a esse destino nobre da pulsão: de um lado, há um resto que resiste à sublimação e que demanda uma satisfação direta da pulsão, de outro, ela não fornece um escudo impenetrável contra o sofrimento. Alguns textos poderiam nos fazer pensar numa espécie de reconciliação do indivíduo com a civilização na medida em que a sublimação impede a renúncia pulsional, mas com a segunda tópica, a angústia de castração, a pulsão de morte, o supereu - um limite interno é postulado ao princípio de prazer e uma sublimação sem conflito é inconcebível (Cf. FREUD, 1971).

No seminário VII, sobre a ética, o vazio é colocado como determinante para toda sublimação. "Toda arte caracteriza-se por um certo modo de organização em torno do vazio", diz Lacan (1986, p. 45). O vazio representa a Coisa e a sublima- 
ção será então definida na sua referência à Coisa. Trata-se de saber qual é esse vazio. A Coisa situa-se entre o real e o significante. "Revela-se então que o vazio não tem somente uma função espacial, mas também simbólica. Ele é da ordem do real, e a arte utiliza o imaginário para organizar simbolicamente o real. Ele está entre o real e o significante" (REGNAULT, 1997, p. 26).

A sublimação consiste em substituir, ao vazio central de das Ding, objetos. Lacan procede, nesse seminário, à enumeração dos termos capazes de ocupar esse lugar do vazio que é das Ding - a mãe, as caixas de fósforos de Prévert, etc. A sublimação é então compreendida a partir de das Ding, o que significa situá-la além do princípio de prazer. Temos aí um dos paradigmas do gozo na psicanálise, o paradigma do gozo impossível, que acentua a disjunção entre o significante e o gozo (Cf. MILLER, 1999).

Esse paradigma situa a Coisa do lado do gozo. Vemos a oposição entre a libido enquanto desejo, ligada aos significantes, e a libido enquanto das Ding, fora significante. O princípio do prazer é visto, de uma certa forma, como uma barreira natural ao gozo. J. A. Miller vê aí uma oposição entre a homeostase do prazer e os excessos de gozo, entre o que é ilusão - do prazer, do significante, do imaginário e o que é real.

Assim das Ding introduz o gozo enquanto real, significando que a satisfação pulsional não se encontra nem no simbólico, nem no imaginário, ela é da ordem do real. Tanto a ordem simbólica quanto a ordem imaginária são construídas contra o gozo real, para conter este gozo. Segundo Miller, o seminário sobre a ética introduz um novo paradigma do gozo que pode ser chamado de paradigma do gozo impossível, dito de outro modo, do gozo real. Das Ding é um real mudo, vazio, fora do simbólico. A concepção de gozo desenvolvida nesse seminário acentua uma disjunção entre o significante e o gozo, sendo este último fora do sistema significante, absoluto, cujo acesso só é possível por uma transgressão. Ora isolar a Coisa como fora do simbólico comporta um paradoxo: como pensar a relação entre o significante e o que é fora da simbolização?

A conceitualização do objeto $a$ responde a essa questão. Se no seminário da ética, o gozo é apresentado como absoluto, acessível somente pela transgressão, no seminário dos quatro conceitos ele é fragmentado, temos o objeto $a$. Ao invés de um acesso ao gozo pela transgressão, temos um caminho pela pulsão pensada como um trajeto de ida e vinda em torno do objeto. Trata-se de um trajeto que vai de das Ding, como gozo impossível, disjunto do significante, ao objeto $a$, como possibilidade de inscrição do gozo, delimitação e condensação do gozo fragmentado.

Ora, a noção de sublimação nos diz que algo insiste na obra que não é o retorno do recalcado e que, sem ter sido recalcado está lá, algo do real. Vale dizer que não se trata de confundir inconsciente e recalcado, tudo o que é recalcado é inconsciente, mas tudo que é inconsciente não é recalcado. $\mathrm{O}$ inconsciente possui uma parte dele mesmo sempre fora da consciência. A escrita tem relação com esta zona do inconsciente que, sem ter sido recalcada, é inconsciente, não-sabido, não banido da consciência, mas desde sempre fora da consciência. 
Quando Clarice escreve, ela toca o território do que nunca existiu. Trata-se de uma não consciência do que se escreve, a escrita fazendo-se a partir do não saber, do que nunca existiu, como Clarice mesma diz:

Escrever é tantas vezes lembrar-se do que nunca existiu. Como conseguirei saber do que nem ao menos sei? assim: como se me lembrasse. Com um esforço de memória, como se eu nunca tivesse nascido. Nunca nasci, nunca vivi: mas eu me lembro, e a lembrança é em carne viva. (LISPECTOR, 1999, p. 385)

Em busca do que nunca existiu, de uma memória que não é feita de palavras mas de traços, de restos, do que se inscreve no real do corpo, Clarice constrói uma escrita cujo voto impossível é atingir o real. Podemos pensar que não se trata de um retorno do recalcado, que a obra não seria formação do inconsciente e assim coisa a se interpretar, mas simplesmente coisa que se apresenta em sua opacidade. Consequentemente, a arte seria não interpretável e seria abordável pelo viés do objeto $a$ (MILLER, 1988).

Jacques Alain-Miller (1988) propõe, em Sept remarques sur la création, que a arte deve ser situada do lado da produção, ou seja, do objeto. O mais complicado seria pensá-lo em relação à literatura. Esta seria a contribuição de Lacan, segundo Miller, contrariamente a Freud que sempre teria tomado a arte pela via da formação do inconsciente. Efetivamente, é o que se avança sobre Joyce, sua arte não seria interpretável visto ser ele um desabonado do inconsciente.

Nesse sentido, a tentativa de interpretação analítica torna-se pouco pertinente e a obra surge ela mesma como tendo um poder de interpretação. Trata-se de tirar todas as conseqüências possíveis desta afirmação. Não penso que toda obra de arte deva ser tomada pela via do objeto $a$, mas que um certo tipo de arte, e falo aqui de uma certa literatura que se faz no século XX e XXI e que se apresenta em sua opacidade, que quer se livrar do significante e da representação, orientando-se na direção de uma monstração, seria a tomar mais pelo objeto do que pelo significante (WAJCMAN, 1984, 1986, 1996, 1997, 1998 ; MAHJOUB-TROBAS, 1994). A partir daí, a obra coloca questões e detém repostas que concernem à psicanálise. Através da arte, a psicanálise busca responder não a questões de ordem artística, mas a problemas encontrados no quadro mesmo da prática analítica, no que me concerne aqui, questões sobre as mulheres e o feminino: a relação com o gozo e com a castração, a inexistência do Outro sexo, o paradigma do falo na diferenciação dos sexos, o final de análise e as figuras clínicas do feminino, entre outras.

Nesse mesmo texto, Jacques-Alain Miller propõe algumas linhas gerais sobre a criação neurótica e a criação psicótica. A primeira constituiria-se sob fundo da castração, toda criação nascendo da falta a ser que caracteriza o sujeito dividido pela linguagem. Ela é feita assim a partir do vazio para contê-lo. A segunda faz-se sob fundo da forclusão, seu paradigma sendo James Joyce cuja arte funcionaria como sintoma capaz de manter enodados o real, o simbólico e o imaginário. Haveria uma criação que se faz sob o fundo o vazio e uma outra que se faz sob fundo do nada. 
A arte seria não a expressão do sujeito, como quer uma certa noção da sublimação, mas sua redução a objeto. Teríamos então um objeto que causa o sujeito em sua divisão: $a \rightarrow \$^{2}$. A obra seria "um objeto que realiza um ato, um produto que é uma causa" (WAJCMAN, 1998). Isto seria válido para o artista e para o amante da arte.

Gérard Wajcman propõe pensar a obra de arte não pela via do significante, mas pela via do objeto, e mesmo do objeto $a$. Em seu livro, L'objet du siècle (1998), ele toma duas obras de arte, Roda de bicicleta e Quadrado negro sob fundo branco, como paradigmas da tese segundo a qual a obra de arte contemporânea deve ser pensada não como coisa a interpretar mas como objeto pensante. Essas obras não estão mais ocupadas em refletir sobre si mesmas, mas visam, com brutalidade, o real. O autor propõe falar em "obras da arte", acentuando o múltiplo, ao invés de "obras de arte", expressão que enfatiza a arte como conjunto. Ele nos fornece duas razões para isto: a primeira é que nenhuma obra tem valor de exemplo, toda obra sempre deve ser considerada nela mesma, a segunda é que na arte só há teoria de uma obra. O que nos leva a uma lógica do caso clínico - a cada obra, sua teoria.

Mas uma outra questão leva a falar em "obras da arte". Falar de "obras da arte" é conceber um objeto como produto de uma atividade, de um saber, de uma mão, etc. Wajcman quer promover a idéia de que esse produto realiza ele mesmo uma obra, tem ele mesmo um efeito sobre os sujeitos. Trata-se de pensar a obra não mais como o que nos fornece uma interpretação do mundo mas como o que pode transformar nosso olhar. O que faz gozar, mas o que faz também ver e ouvir. Essas obras implicariam o espectador e o leitor naquilo que eles vêem e ouvem como sujeitos. Estamos longe de uma noção de sublimação que teria como efeito a contemplação passiva de nossos fantasmas transformados em arte. Ora isso quer dizer que o sujeito não está na obra, nem na interpretação da obra, nem em seus personagens ou em suas imagens, mas na voz e no olhar aos quais ele se vê reduzido pela obra. O sujeito é causado pela arte.

Parece-me que, nesse caso, a obra pode ser pensada como inscrição do objeto $a$, como esse pequeno pedaço de gozo que viria inscrever-se em algum lugar. Situar a obra do lado do objeto e não do lado do significante diz respeito, para Wajcman, às artes visuais e não à literatura. Entretanto, ele afirma que talvez uma certa literatura poderia ser aí situada.

Evidentemente, a pintura situa-se mais facilmente do lado do objeto $a$ que a literatura, sempre colocada do lado do significante. Há que se assinalar entretanto que a escrita de Clarice Lispector é inelutavelmente faltosa em relação ao que ela quer dizer, ao que ela quer ser. Sua obra tende à depuração da fantasia e da narrativa, da linguagem mesmo, para não ser nada além de som, música, ritmo - voto impossível.

Em Clarice Lispector, temos uma escrita na qual a tensão entre o significante e seu além se faz massivamente presente, sua marca sendo menos a narrativa presa a um certo enredo imaginário e suas categorais literárias tradicionais do que um certo ritmo, uma certa sonoridade que assinala em direção ao objeto. Talvez daí 
venha sua fascinação pela música ou pela pintura. Não por acaso, Clarice começou a pintar no final de sua vida, no período em que escreveu Agua Viva (LISPECTOR, 1973). Todo um esforço em atingir o silêncio, o mutismo, o além das palavras parece concentrar-se nesse momento.

É verdade que a fantasia, apontada por Freud como a fonte do material do escritor, é ficção protetora que fixa o gozo. Contudo parece-me que, em Clarice, trata-se menos de desvendar as fantasias atrás da elaboração literária do que perseguir a dissolução do sujeito na matéria viva da língua para se transformar em uma voz.

\section{Clarice Lispector e a vocaÇ̃̃o do esCritor}

A luz das considerações feitas, podemos nos perguntar sobre o que o artista nos ensina. Uma reposta possível seria: ele nos ensina sobre a sua relação com a arte, sobre a sua resposta à falta e à castração, sobre a verdade do seu modo de gozo. Clarice Lispector nos ensina sobre sua verdade que não é outra coisa senão o que insiste e se repete ao longo de sua obra.

Em sua obra, uma questão retorna incessantemente: não porque eu escrevo, mas porque eu não escrevo. Dito de outra forma, porque não faço como a maioria das pessoas fazem - não escrever. Sobre sua atividade de escrita, Clarice (LISPECTOR, 1999, p. 134) escreve:

Eu disse uma vez que escrever é uma maldição. Não me lembro porque exatamente eu disse, e com sinceridade. Hoje repito: é uma maldição mas uma maldição que salva. [...] É uma maldição porque obriga e arrasta como um vício penoso do qual é quase impossível se livrar, pois nada o substitui. E é uma salvação. [...] Escrever é procurar entender, é procurar reproduzir o irreproduzível, é sentir até o último fim o sentimento que permaneceria apenas vago e sufocador. Escrever é também abençoar uma vida que não foi abençoada.

Esse trecho nos fala de uma existência que se faz na e pela escrita. Não só a escrita é um modo de compreensão do mundo, mas ela é sobretudo um modo de existir, de abençoar uma vida que não foi abençoada e que, sem a escrita, morreria. A escrita seria portanto o que salva e poderíamos crer que estamos próximos de uma concepção da sublimação que a quer destino feliz da pulsão. Entretanto, o paradoxo concentra-se na tensão presente na tentativa de definição de Clarice que aproxima o par de oposições maldição e benção - a escrita é "uma maldição que salva"3.

Uma das razões dadas por Clarice a seu ato de escrever é: "porque eu não posso ficar muda". Há, na sua escrita, um degrau acima, o silêncio, a ambição mais inacessível: não escrever (Cf. LISPECTOR, 1999, p. 414). Clarice aspira ao silêncio, ao mesmo tempo em que vê na escrita a única possibilidade de vida. Temos uma escrita que anseia pelo seu fim, pelo silêncio. Ora, fiel a sua aspiração, a escrita de Clarice persegue o silêncio que habita as palavras, busca não abafá-lo, sabendo contudo da impossibilidade de seu voto. 
Parece que estamos longe da suposta satisfação da sublimação. Porque a sublimação nos deixa sem recurso para pensarmos a posição subjetiva de Clarice Lispector diante da criação? Diz-se do artista que ele é aquele capaz de dar existência ao que se tem de mais singular, seu modo de satisfação. Podemos dizer, e hoje ninguém duvidaria, que não há destino feliz da pulsão e menos ainda uma satisfação garantida para o artista. Permanece entretanto a questão de se saber como podemos falar ainda em sublimação quando a beleza não se encontra mais no centro da arte. A noção de sublimação parece pouco pertinente para se pensar uma certa arte que se faz no século XX. Como podemos falar de função consoladora da arte, apaziguadora do mal-estar e compensadora do sacrifício ao qual o homem deve se submeter para viver em sociedade? A arte parece menos acalmar e adormecer do que incomodar e desconcertar, como nos diz Barthes a propósito dos textos de gozo que nos colocam em estado de perda e não em estado de contentamento (BARTHES, 1973). O aparelho teórico do qual dispõe o psicanalista seria pertinente para abordar esta arte? Parece-nos que a noção de sublimação só pode nos ser útil se for redimensionada e relativisada.

Que a psicanálise falando de arte se refira a um sistema clássico não significa que os conceitos psicanalíticos sejam inoperantes para se pensar as obras do nosso século, mas que é preciso recolocar as questões e rever os conceitos. O caráter precário, se podemos dizer, do conceito de sublimação para dar conta da criação nos parece vir da redução que ele opera buscando, por um lado, explicar o enigma da arte pela psicanálise e pelos fenômenos psíquicos e, por outro, de uma idealização do artista como ser capaz de transformar seus sintomas e seus fantasmas em gozo compartilhado. Permanece o fato que o gozo é também desprazer e pulsão de morte e que a arte seria algo a situar mais do lado do além do princípio do prazer, do excesso, do que não serve para nada, modo como definimos o gozo.

A arte parece trabalhar hoje por um esvaziamento, por uma depuração da palavra e do objeto, ao invés da sua idealização ou elevação. Gérard Wajcman, em seu artigo La ressemblance et le moderne (WAJCMAN, 1996), fala de uma deflação do Imaginário da qual a arte moderna seria testemunha. Trata-se de uma arte que nada quer dizer nem representar, que desconforta, incomoda e inquieta, distanciando-se do que seria consolação ou apaziguamento. Esta arte inaugura uma nova dimensão da arte distanciada daquela da representação, sendo mais bem descrita como uma apresentação na qual se trataria simplesmente de tornar presente. Wajcman nos propõe então um outro modo de interrogação da obra de arte: não mais "O que isto significa?", mas "O que eu vejo?", e eu acrescento, "O que eu escuto?". Não é a esta postura que nos convidam as manifestações clínicas atuais, a uma clínica menos do sentido do que do real?

O efeito produzido consiste na substituição da interpretação e da significação por uma interrogação sobre a posição do sujeito, escritor ou leitor, diante da obra. Nem símbolo, nem imagem, nem significação, nem semelhança, a obra aparece como presença, objeto. A psicanálise interrogar-se-ia não mais sobre o artista e a significação da obra, mas sobre o sujeito, o artista e o amante da arte, e sobre a obra ela mesma. Este modo de interrogação nos parece bem mais pertinente: não a busca de uma significação feminina da obra de Clarice, mas o olhar atento às 
questões colocadas por suas obras em relação ao feminino e ao modo de relação destes sujeitos com a criação artística. É a obra que interroga e não o psicanalista.

Em diversos momentos de sua obra, Clarice declara que a escrita não lhe trouxe a paz tão procurada. Podemos encontrar diversas declarações em que o caráter ambíguo e contraditório da escrita se faz sentir: pertencimento e nãopertencimento, eu e não-eu, lugar da existência e do apagamento, da fala e do mutismo.

Maurice Blanchot concebe a obra não como lugar da afirmação do eu, mas como potência que rapta o escritor. A escrita como lugar de existência é um lugar no qual reina a ambigüidade, ela é essencial, ao mesmo tempo em que parece fútil e vazia (BLANCHOT, 1995a, 1995b). Segundo Maurice Blanchot, a obra é uma potência e uma exigência que conduz o sujeito para fora de si, ele é despossuído. Quando ele entra no espaço literário, ele está em um espaço no qual ele não vive, nem morre, não começa, nem cessa. Ele se apaga na escrita. Quem escreve "eu"? O escritor é um ser separado do mundo, mas também separado de si mesmo.

Sombra de si mesmo, ele tende a desaparecer diante da potência que é a obra. Ele não faz existir a obra, mas ao contrário é a obra que faz existir alguém que só existe em relação a ela. Blanchot fala de désœuvrement. Trata-se mais de um rapto do eu, do qual nos fala Clarice Lispector, do que da manifestação de um eu total e unificado. "O que procuro? Procuro o deslumbramento. O deslumbramento que eu só conseguirei através da abstração total de mim" (LISPECTOR apud BORELLI, 1981, p. 79), diz Clarice.

Ler a noção freudiana de sublimação a partir de Clarice é perceber o espaço literário como espaço de existência que, longe de ser lugar do eu, é lugar do nãoeu, lugar da ausência, da presença ausente, do apagamento. O espaço literário assim entendido não poderia constituir-se como lugar de existência do feminino? Seria aí que feminino poderia encontrar um lugar privilegiado de inscrição? A escrita cria este espaço não espaço, esta vida fora da vida, este eu fora do eu. Seria este o lugar de existência de Clarice? Por isso penso que o conceito de sublimação, a menos que seja repensado, só pode nos ajudar parcialmente a abordar a relação de Clarice Lispector com a escrita. Permanece uma zona de sombra, de apagamento, de rapto, de algo que assinala um além do princípio do prazer que, mesmo introduzido na noção de sublimação depois da formulação da pulsão de morte, mantém-se como acessório e não essencial no conjunto teórico que define o conceito.

Nesse lugar da ausência, algo do gozo inscreve-se. A obra faria então uma circunscrição de um pedaço de gozo. Nesse sentido, trata-se menos de uma sublimação do que de um désœuvrement, como diz Maurice Blanchot, menos de uma elevação das forças do "isso" em direção aos ideais da cultura do que um fracasso do simbólico para dar conta do real.

A obra de Clarice Lispector coloca questões sobre as mulheres e a criação assinalando o espaço da escrita como lugar possível de existência para o Outro sexo. Procedendo dessa forma, ela abala a ordem fálica. A sublimação, que é pas- 
sagem do sensorial ao intelectual, transforma-se, num movimento de inversão, em redescoberta do mundo sensorial e corporal da mãe, revelação "dessa lembrança do que nunca existiu", ou ainda "desse saber impossível da infância". Repensar a sublimação implica nisso - resituá-la do lado do feminino, como o que inaugura, não a abstração ou a intelectualização tão caras à lógica fálica, dito de outro modo, ao pai, mas a afirmação da existência do sensorial, do corpo, desse mundo antes do recalcamento que nunca existiu e que entretanto sempre esteve lá, dito de outro modo, a mãe. A criação no feminino é menos um modo de subjetivação do que um modo de exibição da falta a ser do sujeito.

A distinção proposta por Jacques-Alain Miller (1988) entre a criação neurótica e a criação psicótica, gostaria de acrescentar uma outra que seria a criação no feminino, feita sob o fundo não da castração ou da falta, nem da forclusão, mas sob fundo do buraco, de um vazio mais real e angustiante do que a falta da castração que teria relação com a parte da mulher que não se recobre pela referência à castração e ao falo. A arte de Clarice Lispector, parece-me, situa-se nessa terceira via, mais próxima do buraco do que da falta a ser e da castração, mas não referida por isso à forclusão porque inclui o falo.

Isto nos conduz a passar da sublimação à criação, do significante ao objeto, do eu ao não-eu, do prazer ao gozo. Uma existência que se afirma pela negação, pela ausência e pelo apagamento não saberia estar em outro lugar senão nesse espaço neutro e inalcançável que é o espaço literário. Trata-se aqui não de subjetivação ou de apropriação do eu, mas de exibição da falta a ser do sujeito. A função primeira da escrita é menos a constituição do eu do escritor do que sua perda no texto e a inscrição de um gozo. Em Clarice, este gozo inscreve-se no texto pela voz.

\footnotetext{
Notas

${ }^{1}$ Para uma melhor compreensão acerca da "estética do sopro", remeto à minha tese de doutorado L'esthétique du souffle chez Clarice Lispector: Un certain destin du féminin. Nela defino a "estética do sopro" como uma poética que busca uma certa musicalidade das palavras, uma respiração ofegante, ou ainda, um gozo da linguagem mais do que uma construção fantasmática

${ }^{2}$ Esta idéia foi tema de discussão em um cartel "Psicanálise e cultura" composto por Gilson Iannini, Musso Greco, Juliana Meirelles, Cristina Marcos e Lúcia Grossi. Grossi busca aproximar o discurso da arte do discurso do analista na medida em que eles situam o objeto $a$ no lugar de agente e a divisão do sujeito como efeito do discurso.

${ }^{3}$ Sobre o tema da escrita como o que salva e condena, ver La pharmacie de Platon (1972). Derrida faz aí a análise do termo utilizado por Platão em Fedro para caracterizar a escrita, phármakon. A tradução de phármakon deve considerar os dois sentidos presentes na palavra - medicamento mas também veneno, ao mesmo tempo benéfico e nocivo.
} 


\section{REFERÊNCIAS}

BARTHES, R. Le plaisir du texte. Paris: Seuil, 1973.

BLANCHOT, M. L'espace littéraire. Paris: Gallimard Folio essais, 1995a. Le livre à venir. Paris: Gallimard Folio essais, 1995 b.

BORELLI, O. Esboço para um possível retrato. Rio de Janeiro: Nova Fronteira, 1981.

DERRIDA, J. La pharmacie de Platon. Paris: Seuil, 1972.

FREUD, S. La morale sexuelle civilisée et la maladie nerveuse des temps modernes. In: . La vie sexuelle. Paris : PUF, 1999. p. 28-46. . Malaise dans la civilisation. Paris: PUF,1971. Pulsions et destins des pulsions. In: . Métapsychologie. Paris: Gallimard Folio essais, 1968. p. 11-43.

LACAN, J. (1959-1960) Le séminaire - livre VII: l'éthique de la psychanalyse. Paris: Seuil, 1986. $\overline{\text { Oct. } 1961 .}$

Maurice Merleau-Ponty. Temps Modernes, Paris, n. 184-185, p. 245-254,

LISPECTOR, C. A descoberta do mundo. Rio de Janeiro: Rocco, 1999. Agua viva. Paris: Des Femmes, 1973. Edição bilíngüe.

MAHJOUB-TROBAS, L. L'œuvre au féminin. Barca, Paris, n. 2, p. 103-114, maio1994.

MILLER, J.A. Les six paradigmes de la jouissance. Revue de la cause freudienne, Paris, n. 43, p. 7-29, out. 1999. Avr. 1988

Sept remarques sur la création. La lettre mensuelle, Paris, n. 68, p. 9-13,

MOREIRA-MARCOS, C. L'esthétique du souffle chez Clarice Lispector: un certain destin du féminin. 2005. Tese (Doutorado em Psicopatologia Fundamental e Psicanálise)-Universidade de Paris VII, Paris, 2005.

REGNAULT, F. Conférences d'esthétiques lacanienne. Paris: Agalma, 1997.

WAJCMAN, G. La ressemblance et le moderne. Barca, Paris, n. 7, p. 95-120, nov. 1996.

. L'objet du siècle. Paris: Veridie, 1998.

. Narcisme ou le fantasme de la peinture. In: 


\section{Cristina Marcos}

WAJCMAN, G. L'or d'Atalante: art et fantasme. Paris: Champ Vallon, 1984. p. 107-126.

Portrait de l'objet aboli. Quarto : Revue de psychanalyse Ecole de la Cause Freudienne - ACF en Belgique, Paris, n. 63, p. 74-78, Oct. 1997. . Stylus. Analytica, Paris, n. 43, p. 77-89, 1986.

Recebido em: julho/2006

Aceito em: dezembro/2006 